\title{
OPTIMALISASI PROSES PRODUKSI H-BEAM DENGAN METODE PERT (PROGRAM EVALUTION REVIEW TECHNIQUE) DAN CPM (CRITICAL PATH METHOD) DI PT. MULCINDO STEEL INDUSTRY
}

\author{
Sofiyanurriyanti ${ }^{1)}$, Nuril Hidayati Ningsih ${ }^{2)}$ \\ 1) Jurusan Teknik Industri, Universitas Teuku Umar \\ 2) Jurusan Teknik Industri, Universitas Qomaruddin Gresik \\ Email: sofiyanurriyanti@utu.ac.id ${ }^{1)}$, nurielhidayah1397@gmail.com ${ }^{2)}$
}

\begin{abstract}
ABSTRAK
Perencanaan kegiatan proyek dilakukan setiap pekerjaan salah satunya adalah kegiatan perencanaan proyek. Penetuan perencanaan kegiatan proyek ini berfungsi untuk mengoptimalkan waktu durasi alokasi pelaksanaan yang diselesaikan dengan waktu optimal sehingga suatu proyek bisa berjalan dengan lancar dan tepat waktu sehingga tidak terjadinya keterlambatan waktu. Tujuan penelitian ini adalah untuk menentukan proses produksi H-Beam di PT. Mulcindo Steel Industry dan menentukan waktu penyelesaian proses produksi H-Beam dengan menggunakan metode PERT (Project Evaluation and Review Technique) dan CPM (Critical Path Method). Kegiatan proses produksi besi jenis H-Beam ini terdapat hubungan ketergantungan aktivitas satu dengan yang lain seperti Pengecekan Plat, Perencanaan Pemotongan Jalur Plat, Pemotongan Plat, Penghalusan Sisi Plat, Penyambungan Pertama Bagian Flange ke Bagian Web, Penyambungan ke-2 Bagian Flange ke Bagian Web, Pengelasan System SAW, Proses Repair, Proses Pelurusan Produk, Proses Akhir Pengecekan Dimensi, Proses Memberi Label Barang. Hasil analisis dalam penelitian ini menunjukan metode PERT dan CPM dapat diketahui ada 11 kegiatan proses produksi yang dilakukan selama 160 menit dan ada satu slack=0 yang berada dikegiatan $G$, sehingga lintasan kritis pada kegiatan proses produksi besi baja $H$-beam adalah $A-C-D-E-F-G-H-I-J-K$ dengan waktu penyelesaian proses selama 160 menit
\end{abstract}

Kata kunci: Perencanaan, Pengendalian, Proses produksi, CPM dan PERT

\section{Pendahuluan}

Setiap proses perencanaan dan pelaksanaan suatu proyek kontruksi yang dilakukan pada setiap pekerjaan melibatkan beberapa faktor yang harus dipertimbangkan antara lain biaya, waktu dan mutu. Proses alokasi durasi perencanaan dan pelaksanaan tergantung pada setiap pekerjaan masing masing dan tergantung pada jadwal waktu durasi alokasi pelaksanaan di lapangan [1]. Dalam pelaksanaan prosesnya juga sangat penting melibatkan berbagai tenaga, waktu dan uang yang sangat tidak sedikit dibutuhkan [2]. Setiap proyek yang akan dijalankan oleh perusahaan mungkin akan mengalami kesulitan dalam mengelolaan sumber daya yang perlu dilakukan oleh proyek. Perencanaan yang biasanya didahului dengan aktifitas peramalan, pengorganisasian, pelaksanaan kegiatan yang diikuti dengan proses pengarahan, pemberian motifasi dan lain-lain [3].

Ketidakpastian suatu proyek dalam pelaksanaan proyek cederung risiko terhadap menerapkan pada proses pelaksanaan suatu proyek sesuai dengan karateristik proyek. Besar kecilnya suatu proyek yang dijalani maka semakin besar juga tantangan dalam suatu proyek yang akan dijalankan [4]. Manajemen proyek adalah pengelolaan atau tatalaksana, dari proses perencanaan, pengorganisasian, pengarahan, serta pengendalian [5]. Hambatan dalam pelaksanaan proyek membuat dampak yang serius dan memiliki pengaruh yang lebih besar dalam jalannya setiap proyek [6]. Optimasi waktu dan biaya yang akan dilakukan adalah mempercepat durasi proyek dengan penambahan biaaya seminimal mungkin dengan perbedaan umur pelaksanaan proyek dengan umur rencana proyek yang telah ditetapkan [7]. Keterlambatan akan berpengaruh tidak hanya pada biaya tetapi juga pandangan konsumen akan kredibilitas pada perusahaan itu sendiri yang akan berdampak pada kelangsungan hidup pada perusahaan [8]. Dalam

Copyright (C) 2019, Kaizen : Management Systems \& Industrial Engineering Journal ISSN 15222-96806 (print), ISSN $155222-95973$ (online) 


\section{KAIZEN : MANAGEMENT SYSTEMS \& INDUSTRIAL ENGINEERING JOURNAL VOL. 2 NO. 2 TEKNIK INDUSTRI UNIVERSITAS PGRI MADIUN}

suatu perencanaan dan pengendalian proyek salah satu metode yang tepat digunakan adalah metode PERT (Project Evaluation and Review Techique) dan CPM (Critical Path Method) pada jalur kritis [9].

PT Mulcindo Steel Industry adalah sebuah perusahaan baja dan perusahaan jasa galvanis berskala internasional yang terpercaya, dan dapat dibanggakan dengan menyediakn produk dan jasa yang berkualitas dan berinovasi. Jenis baja yang diproduksi adalah: Atap Gelombang, Genteng Metal, Besi Kanal C, Rangka Plafon, Rangka Atap Baja Ringan, Tiang Penerangan Jalan Umum (PJU), Monopole (Tiang Lampu Sorot dan Antena), Lampu Persimpangan Jalan dan Penunjuk Jalan, Balok Pengaman Jalan, Welded Beam/ H-Beam, Deck Plate, Girder untuk Crane, Tower Telekomunikasi dan PLN, Jembatan Baja. Selain memproduksi berbagai jenis produk baja PT Mulcindo Steel Industry juga menyediakan jasa yaitu: Jasa Pelapisan Galvanis (Hot Dip Galvanizing) dan Jasa Pemotongan baja (Slitter Coll) (PT Mulcindo Steel Industry). Permasalahan yang mungkin muncul di perusahaan PT. Mulcindo Steel Industry adalah dalam hal proses mengidentifikasi pembuatan H-Beam terdapat keterlambatan penyelesaian karena faktor sumber daya manusia yang kurang dan permintaan konsumen untuk produk selesai sebelum waktu yang ditentukan hal ini dapat berpengaruh terhadap penyelesaian produk.

Penelitian ini terfokus pada satu produk yaitu: Welded Beam/ H-Beam. Welded Beam/ H-Beam adalah salah satu balok yang sering kali disebut dengan hot rolled yang dilengkapi dengan penampang yang berbentuk $\mathrm{H}$ yang sering digunakan sebagai penahan struktur bangunan, tiang pancang, dan juga komposit beton. Selain digunakan pada konstruksi, H-Beam juga dapat digunakan pada rel kereta dengan menggunakan ketebalan khusus untuk menahan beban dari kereta yang berjalan diatasnya. Untuk meningkatkan kembali penyelesaian produk $\mathrm{H}$-Beam ini maka diperlukan adanya analisis optimalisasi durasi pengerjaan yang berfungsi untuk mengetahui berapa lama produk H-Beam dapat diselesaikan secara optimal, untuk mencari adanya kemungkinan percepatan waktu pembuatan H-Beam, maka dapat menggunakan metode PERT (Project Evaluation and Review Technique) dan CPM (Critical Path Method) yaitu suatu alat manajemen proyek yang digunakan untuk melakukan penjadwalan, mengatur dan mengkoordinasi bagian-bagian pekerjaan yang ada didalam suatu proyek. Teknik PERT adalah suatu metode yang bertujuan untuk sebanyak mungkin mengurangi adanya penundaan, maupun gangguan produksi, serta mengkoordinasikan berbagai bagian suatu pekerjaan secara menyeluruh dan mempercepat selesainya proyek [10]. Sedangkan CPM merupakan metode yang digunakan untuk membantu memperbaiki efisiensi pengerjaan proyekproyek segala ukuran. Oleh karena itu dalam penelitian ini penulis akan menggunakan metode PERT (Project Evaluation and Review Technique) dan CPM (Critical Path Method).

\section{Metode Penelitian}

Dalam penelitian ini penerapan ada beberapa tahap yang dilakukan dalam metodelogi penelitian antara lain studi literatur, pengumpulan data berdasarkan wawancara dan observasi lalu tahap analisa dan pembahasan yaitu aktivitas kegiatan, hubungan ketergantungan antar aktivitas dan waktu kegitatan kemudian pengolahan data mengunakan metode CPM dan PERT dan selanjutnya tahap kesimpulan dan saran.

\section{Hasil dan Pembahasan}

Proses produksi Besi Baja jenis H-Beam terdiri dari banyak proses yang sangat berhubungan satu sama lain. Untuk lebih jelasnya dapat dilihat pada Tabel 1. Dalam proses produksi Besi Baja jenis H-Beam ini terdapat hubungan ketergantungan antar aktivitas satu dengan yang lain dapat dilihat pada Tabel 2. Waktu yang digunakan dalam pelaksanaan proses produksi Besi Baja jenis H-Beam menggunakan waktu kontinyu karena proses produksi yang dilakukan secara terus- menerus. Adapun waktu proses produksi Besi Baja jenis H-Beam dapat dilihat pada Tabel 3. 


\section{KAIZEN : MANAGEMENT SYSTEMS \& INDUSTRIAL ENGINEERING JOURNAL VOL. 2 NO. 2 TEKNIK INDUSTRI UNIVERSITAS PGRI MADIUN}

Tabel 1. Data Proses produksi Besi Baja jenis H-Beam

\begin{tabular}{|c|l|c|l|l|}
\hline Kegiatan & \multicolumn{1}{|c|}{ Penjelasan } & Kegiatan & \multicolumn{1}{c|}{ Penjelasan } \\
\hline A & Pengecekan Plat & G & Pengelasan System SAW \\
\hline B & Perencanaan Pemotongan Jalur Plat & I & Proses Repair \\
\hline C & Pemotongan Plat & \multirow{J}{*}{ Proses Pelurusan Produk } & $\begin{array}{l}\text { Proses Akhir Pengecekan } \\
\text { Dimensi }\end{array}$ \\
\hline D & Penghalusan Sisi Plat & K & Proses Memberi Label Barang \\
\hline E & Penyambungan Pertama Bagian Flange ke Bagian Web & & \\
\hline F & Penyambungan ke-2 Bagian Flange ke Bagian Web & &
\end{tabular}

Perhitungan maju ini dilakukan untuk mengetahui ES yaitu seberapa cepat aktivitas dapat dikerjakan atau dilaksankan, EF yaitu seberapa cepat aktivitas dapat diselesaikan dan perhitungan maju ini juga dapat mengetahui kapan proyek dapat diselesaikan. EF dari kegitatan pendahulu akan menjadi ES untuk kegiatan berikutnya dan bila terdapat aktivitas gabungan maka dipilih durasi yang terpanjang. Untuk perhitungan seluruhnya akan dilakukan dengan menggunakan bantuan Software QM (Quantitative Methods) seperti terlihat pada Tabel 4. Perhitungan maju ini menggunakan rumus pada Persamaan 1.

$$
\mathrm{EF}=\mathrm{ES}+\mathrm{D}
$$

Keterangan :

$\mathrm{EF}($ Earliest Finish $)=$ Waktu penyelesaian kegiatan yang paling cepat.

ES $($ Earliest Start $)=$ Waktu kegiatan yang paling cepat.

Berikut contoh perhitungan maju pada kegiatan $\mathrm{A}, \mathrm{B}$ dan $\mathrm{C}$

a. Kegiatan $\mathrm{A}=\mathrm{ES}+\mathrm{D}=0+3(0$, dikarenakan kegiatan $\mathrm{A}$ merupakan awal peristiwa) $=3$ menit (Maka kegiatan A memiliki $\mathrm{ES}=0$ dan $\mathrm{EF}=3$ ).

b. Kegiatan $\mathrm{B}=3+1(3$, dari ES A dan 1 dari kegiatan $\mathrm{B})=4$ menit (Maka kegiatan $\mathrm{B}$ memiliki $\mathrm{ES}=3$ dan $\mathrm{EF}$ $=1)$.

c. Kegiatan $\mathrm{C}=4+45(4$, dari ES B dan 45 dari kegiatan $C)=49$ menit (Maka kegiatan B memiliki ES $=4$ dan $\mathrm{EF}=45)$

Tabel 2. Hubungan Ketergantungan Antar Aktivitas

\begin{tabular}{|c|l|c|}
\hline Kegiatan & \multicolumn{1}{|c|}{ Penjelasan } & Pendahuluan Langsung \\
\hline A & Pengecekan Plat & - \\
\hline B & Perencanaan Pemotongan Jalur Plat & A \\
\hline C & Pemotongan Plat & B \\
\hline D & Penghalusan Sisi Plat & D \\
\hline E & Penyambungan Pertama Bagian Flange ke Bagian Web & E \\
\hline F & Penyambungan ke-2 Bagian Flange ke Bagian Web & F \\
\hline G & Pengelasan System SAW & G \\
\hline H & Proses Repair & H \\
\hline I & Proses Pelurusan Produk & I \\
\hline J & Proses Akhir Pengecekan Dimensi & J \\
\hline K & Proses Memberi Label Barang & \\
\hline
\end{tabular}

Copyright (C) 2019, Kaizen : Management Systems \& Industrial Engineering Journal ISSN 15222-96806 (print), ISSN $155222-95973$ (online) 


\section{KAIZEN : MANAGEMENT SYSTEMS \& INDUSTRIAL ENGINEERING JOURNAL VOL. 2 NO. 2 TEKNIK INDUSTRI UNIVERSITAS PGRI MADIUN}

Tabel 3. Rincian Waktu Masing- masing Kegiatan

\begin{tabular}{|c|l|c|c|}
\hline Kegiatan & \multicolumn{1}{|c|}{ Penjelasan } & $\begin{array}{c}\text { Pendahuluan } \\
\text { Langsung }\end{array}$ & $\begin{array}{c}\text { Waktu } \\
\text { (Menit) }\end{array}$ \\
\hline A & Pengecekan Plat & - & 3 \\
\hline B & Perencanaan Pemotongan Jalur Plat & A & 1 \\
\hline C & Pemotongan Plat & B & 45 \\
\hline D & Penghalusan Sisi Plat & C & 2 \\
\hline E & Penyambungan Pertama Bagian Flange ke Bagian Web & D & 11 \\
\hline F & Penyambungan ke-2 Bagian Flange ke Bagian Web & E & 8 \\
\hline G & Pengelasan System SAW & F & 51 \\
\hline H & Proses Repair & G & 10 \\
\hline I & Proses Pelurusan Produk & H & 8 \\
\hline J & Proses Akhir Pengecekan Dimensi & I & 20 \\
\hline K & Proses Memberi Label Barang & J & 1 \\
\hline
\end{tabular}

Perhitungan Mundur ini dilakukan untuk mengetahui LS yaitu mengetahui seberapa lambat kegiatan dapat dilakukan atau dimulai, LF yaitu mengetahui waktu paling akhir kegiatan atau seberapa lambat kegiatan dapat diselesaikan. LF untuk kegiatan paling akhir adalah sama dengan EF untuk kegiatan paling akhir. LF untuk kegiatan pendahulu diperoleh dari LS kegiatan pengikut dan bila terdapat aktivitas bercabang maka dipilih durasi yang terpendek. perhitungan mundur selengkapnya digunakan Software QM (Quantitative Methods) dan dapat dilihat pada Tabel 4. Perhitungan Mundur ini menggunakan rumus pada persamaan 2.

$$
\mathrm{LS}=\mathrm{LF}-\mathrm{D}
$$

Keterangan :

LS $($ Latest Start $)=$ Waktu mulai kegiatan yang paling lambat.

LF $($ Latest Finish $)=$ Waktu penyelesaian kegiatan yang paling lambat.

Dari rumus yang ada maka dilakukan perhitungan mundur untuk aktivitas-aktivitas yang ada dalam proses produksi besi baja jenis $H$-Beam. Berikut contoh perhitungan mundurnya pada kegiatan $\mathrm{K}$, J dan I
a. Kegiatan $\mathrm{K}=\mathrm{LF}-\mathrm{D}=159-20=139$ Menit
b. Kegiatan $\mathrm{J}=\mathrm{LF}-\mathrm{D}=139-8=131$ Menit
c. Kegiatan I = LF $-\mathrm{D}=131-10=121$ Menit

Float Total suatu kegiatan sama dengan waktu selesai paling akhir, dikurangi waktu selesai paling awal atau waktu mulai paling akhir dikurangi waktu mulai paling awal dari kegiatan tersebut. Perhitungan Float Total untuk masing- masing kegiatan pada Proses Produksi Besi Baja jenis H-Beam. Untuk perhitungan selengkapnya menggunakan bantuan Software QM (Quantitative Methods) dan dapat dilihat dalam Tabel 4. Float Total dicari mengunakan rumus pada Persamaan 3.

$\mathrm{TF}=\mathrm{LF}-\mathrm{EF}$ atau TF $=\mathrm{LS}-\mathrm{ES}$

Berikut contoh perhitungan Float Total pada aktivitas A, B dan C
a. Kegiatan $\mathrm{A}=\mathrm{LF}-\mathrm{EF}=3-3=0$ Menit
b. Kegiatan $\mathrm{B}=\mathrm{LF}-\mathrm{EF}=1-1=0$ Menit
c. Kegiatan $\mathrm{C}=\mathrm{LF}-\mathrm{EF}=45-45=0$ Menit 


\section{KAIZEN : MANAGEMENT SYSTEMS \& INDUSTRIAL ENGINEERING JOURNAL VOL. 2 NO. 2 TEKNIK INDUSTRI UNIVERSITAS PGRI MADIUN}

Tabel 4. Hasil Perhitungan Maju, Mundur dan Total Float

\begin{tabular}{|c|c|c|c|c|c|c|}
\hline Kegiatan & $\begin{array}{c}\text { Activity } \\
\text { Time }\end{array}$ & $\begin{array}{c}\text { Early Start } \\
\text { (ES) }\end{array}$ & $\begin{array}{c}\text { Early } \\
\text { Finish (EF) }\end{array}$ & $\begin{array}{c}\text { Late Start } \\
\text { (LS) }\end{array}$ & $\begin{array}{c}\text { Late Finish } \\
\text { (LF) }\end{array}$ & Slack \\
\hline A & 3 & 0 & 3 & 0 & 3 & 0 \\
\hline B & 1 & 3 & 4 & 3 & 4 & 0 \\
\hline C & 45 & 4 & 49 & 4 & 49 & 0 \\
\hline D & 2 & 49 & 51 & 49 & 51 & 0 \\
\hline E & 11 & 51 & 62 & 51 & 62 & 0 \\
\hline F & 8 & 62 & 70 & 62 & 70 & 0 \\
\hline G & 51 & 70 & 121 & 70 & 121 & 0 \\
\hline H & 10 & 121 & 131 & 121 & 131 & 0 \\
\hline I & 8 & 131 & 139 & 131 & 139 & 0 \\
\hline J & 20 & 139 & 159 & 139 & 159 & 0 \\
\hline K & 1 & 159 & 160 & 159 & 160 & 0 \\
\hline
\end{tabular}

Hasil perhitungan yang telah dilakukan maka lintasan kritis pada kegiatan proses produksi Besi Baja jenis $H$ Beam adalah $\mathrm{A}-\mathrm{B}-\mathrm{C}-\mathrm{D}-\mathrm{E}-\mathrm{F}-\mathrm{G}-\mathrm{H}-\mathrm{I}-\mathrm{J}-\mathrm{K}$ dengan waktu penyelesaian proses selama 159 menit. Gambar 1 menunjukkan waktu kegiatan ES, EF, LS dan LF serta lintasan kritis.

Metode PERT tersebut adalah expected duration ( $\left.\mathrm{T}_{\mathrm{e}}\right)$, waktu optimistik (a) waktu paling mungkin (m), dan waktu pesimistik (b), terdapat tiga estimasi waktu untuk masing-masing aktivitas. Dalam metode PERT yang menentukan estimasi tiga angka-angka yaitu dalam waktu optimis (a), waktu paling mungkin (m), dan waktu pesimistik (b), selanjutnya adalah merumuskan hubungan ketiga angka tersebut menjadi satu angka. Perhitungan PERT dapat diperoleh dengan mengunakan rumus pada Persamaan 4. Perhitungan deviasi standart dan varians mengunakan rumus pada persamaan 5 dan 6 .

$$
\begin{aligned}
& \mathrm{T}_{\mathrm{e}}=\frac{\mathrm{a}+4 \mathrm{~m}+\mathrm{b}}{6} \\
& \text { Deviasi Standard }(\mathrm{S})=\frac{1}{6}(\mathrm{~b}-\mathrm{a}) \\
& \text { Varians }\left(\mathrm{S}^{2}\right)=\left[\frac{1}{6}(\mathrm{~b}-\mathrm{a})\right]^{2}
\end{aligned}
$$

Perhitungan PERT $\left(\mathrm{T}_{\mathrm{e}}\right)$, Deviasi Standard $(\mathrm{S})$ dan Variansi $\left(\mathrm{S}^{2}\right)$ selanjutnya digunakan bantuan Software QM(Quantitative Methods) dan hasilnya dapat dilihat pada Tabel 6. Contoh perhitungan PERT ( $\left.\mathrm{T}_{\mathrm{e}}\right)$, Deviasi Standard (S) dan Variansi $\left(\mathrm{S}^{2}\right)$ pada kegiatan A, B dan C adalah sebagai berikut

\section{a. Kegiatan A}

$$
\begin{aligned}
& T_{e}=\frac{a+4 m+b}{6}=\frac{2+(4 \times 3)+4}{6}=3 \\
& S=\frac{1}{6}(b-a)=\frac{1}{6}(4-2)=0,33 \\
& S^{2}=\left[\frac{1}{6}(b-a)\right]^{2}=\left[\frac{1}{6}(4-2)\right]^{2}=0,11
\end{aligned}
$$

c. Kegiatan C

$$
\begin{aligned}
& \mathrm{T}_{e}=\frac{\mathrm{a}+4 \mathrm{~m}+\mathrm{b}}{6}=\frac{44+(4 \times 45)+46}{6}=45 \\
& \mathrm{~S}=\frac{1}{6}(\mathrm{~b}-\mathrm{a})=\frac{1}{6}(46-44)=0,33 \\
& \mathrm{~S}^{2}=\left[\frac{1}{6}(\mathrm{~b}-\mathrm{a})\right]^{2}=\left[\frac{1}{6}(46-44)\right]^{2}=0,11
\end{aligned}
$$

b. Kegiatan B

$$
\begin{aligned}
& \mathrm{T}_{\mathrm{e}}=\frac{\mathrm{a}+4 \mathrm{~m}+\mathrm{b}}{6}=\frac{1+(4 \times 1)+2}{6}=1,17 \\
& \mathrm{~S}=\frac{1}{6}(\mathrm{~b}-\mathrm{a})=\frac{1}{6}(2-1)=0,16 \\
& \mathrm{~S}^{2}=\left[\frac{1}{6}(\mathrm{~b}-\mathrm{a})\right]^{2}=\left[\frac{1}{6}(2-1)\right]^{2}=0,026
\end{aligned}
$$


KAIZEN : MANAGEMENT SYSTEMS \& INDUSTRIAL ENGINEERING JOURNAL VOL. 2 NO. 2 TEKNIK INDUSTRI UNIVERSITAS PGRI MADIUN
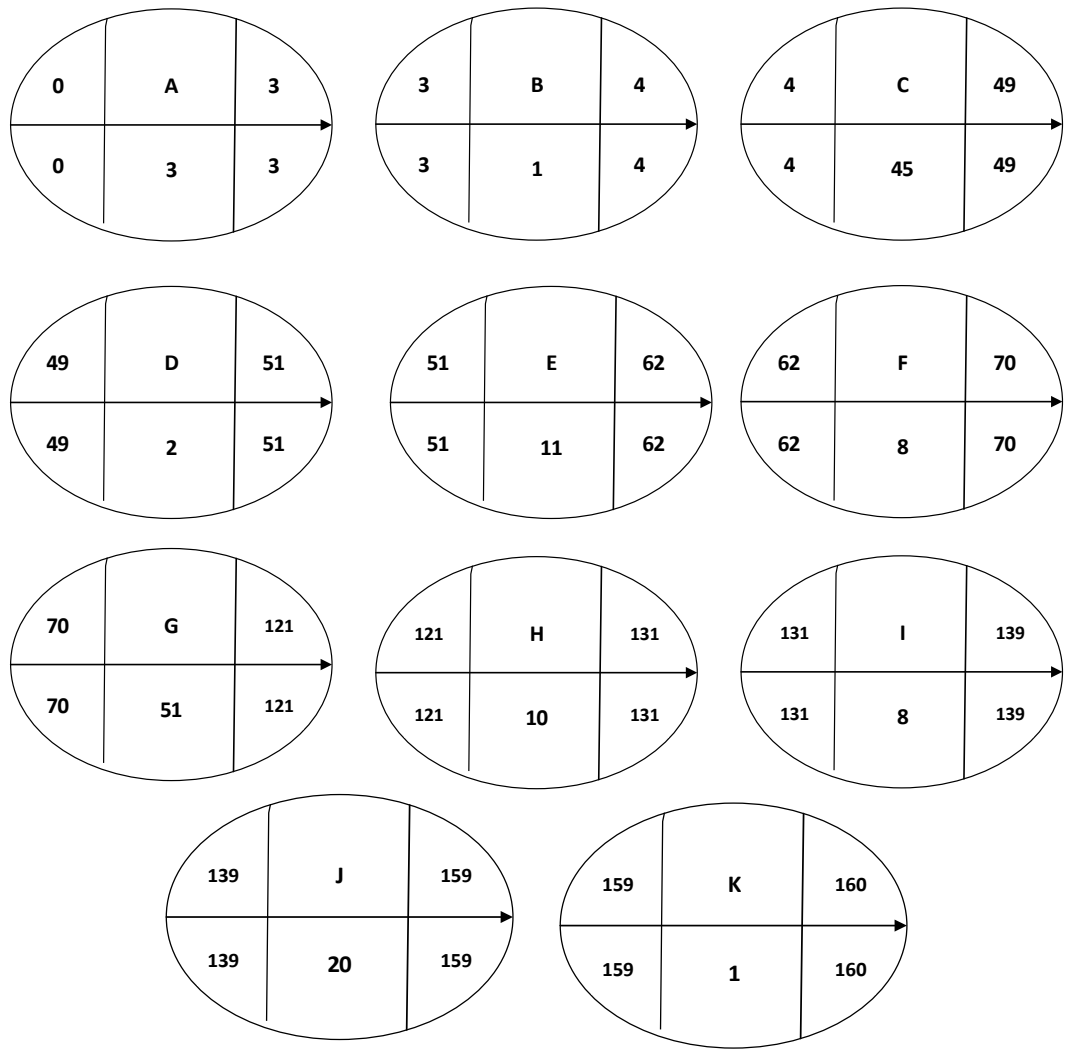

Gambar 1. Lintasan Kritis

Tabel 6. Kurun Waktu yang Diharapkan, Standar Deviasi dan Varians

\begin{tabular}{|c|c|c|c|c|c|c|}
\hline Kegiatan & $\begin{array}{c}\text { Optimistic } \\
\text { Time }(\boldsymbol{a})\end{array}$ & $\begin{array}{c}\text { Most Likely } \\
\text { Time }(\boldsymbol{m})\end{array}$ & $\begin{array}{c}\text { Pessimistic } \\
\text { Time }(\boldsymbol{b})\end{array}$ & $\begin{array}{c}\text { Activity } \\
\text { Time }(\text { Te) }\end{array}$ & $\begin{array}{c}\text { Standard } \\
\text { Deviation }(\boldsymbol{s})\end{array}$ & $\begin{array}{c}\text { Variance V } \\
(\text { te) }\end{array}$ \\
\hline A & 2 & 3 & 4 & 3 & 0.33 & 0.11 \\
\hline B & 1 & 1 & 2 & 1.17 & 0.17 & 0.03 \\
\hline C & 44 & 45 & 46 & 45 & 0.33 & 0.11 \\
\hline D & 2 & 2 & 3 & 2.17 & 0.17 & 0.03 \\
\hline E & 10 & 11 & 12 & 11 & 0.33 & 0.11 \\
\hline F & 7 & 8 & 9 & 8 & 0.33 & 0.11 \\
\hline G & 50 & 51 & 52 & 51 & 0.33 & 0.11 \\
\hline H & 9 & 10 & 11 & 10 & 0.33 & 0.11 \\
\hline I & 7 & 8 & 9 & 8 & 0.33 & 0.11 \\
\hline J & 19 & 20 & 21 & 20 & 0.33 & 0.11 \\
\hline K & 1 & 1 & 2 & 1.17 & 0.17 & 0.03 \\
\hline
\end{tabular}

Tabel 7. menunjukkan hasil rekapitulasi hasil ES, EF, LS, LF dan Slack pada Metode PERT. Hasil pada Tabel 7. kemudian dilakukan pengecekan melalui perbandingan perhitungan dengan bantuan sofhware POM QM. Hasil perhitungan dengan sofhware POM QM dapat dilihat pada Tabel 8. dan Tabel 9. Berdasarkan perhitungan di atas maka dapat diketahui kegiatan- kegiatan yang bersifat kritis sehingga membentuk suatu jalur yang terpanjang. Dengan mengingat bahwa lintasan kritis adalah kegiatan yang mempunyai slack $=0$, maka lintasan kritis pada proses produksi Besi Baja jenis $H$-Beam dengan menggunakan metode PERT adalah $\mathrm{A}-\mathrm{B}-\mathrm{C}-\mathrm{D}-\mathrm{E}-\mathrm{F}-\mathrm{G}-\mathrm{H}-\mathrm{I}-\mathrm{J}$ - K dengan penyelesaian proses produksi selama 160 menit. 
KAIZEN : MANAGEMENT SYSTEMS \& INDUSTRIAL ENGINEERING JOURNAL VOL. 2 NO. 2 TEKNIK INDUSTRI UNIVERSITAS PGRI MADIUN

Tabel 7. Perhitungan ES, EF, LS, LF dan Slack pada Metode PERT

\begin{tabular}{|c|c|c|c|c|c|c|c|}
\hline $\begin{array}{c}\text { Kegiatan } \\
\text { Project }\end{array}$ & $\begin{array}{c}\text { Activity } \\
\text { Time }\end{array}$ & $\begin{array}{c}\text { Early } \\
\text { Start }\end{array}$ & $\begin{array}{c}\text { Early } \\
\text { Finish }\end{array}$ & Late Start & $\begin{array}{c}\text { Late } \\
\text { Finish }\end{array}$ & Slack & $\begin{array}{c}\text { Standard } \\
\text { Deviation }\end{array}$ \\
\hline A & 3 & 0 & 3 & 48 & 51 & 48 & 0.33 \\
\hline B & 1.17 & 0 & 1.17 & 49.83 & 51 & 49.83 & 0.17 \\
\hline C & 45 & 0 & 45 & 6 & 51 & 6 & 0.33 \\
\hline D & 2.17 & 0 & 2.17 & 48.83 & 51 & 48.83 & 0.17 \\
\hline E & 11 & 0 & 11 & 40 & 51 & 40 & 0.33 \\
\hline F & 8 & 0 & 8 & 43 & 51 & 43 & 0.33 \\
\hline G & 51 & 0 & 51 & 0 & 51 & 0 & 0.33 \\
\hline H & 10 & 0 & 10 & 41 & 51 & 41 & 0.33 \\
\hline I & 8 & 0 & 8 & 43 & 51 & 43 & 0.33 \\
\hline J & 20 & 0 & 20 & 31 & 51 & 31 & 0.33 \\
\hline K & 1.17 & 0 & 1.17 & 49.83 & 51 & 49.83 & 0.17 \\
\hline
\end{tabular}

Tabel 8. Perhitungan dari Software POM QM

\begin{tabular}{|c|c|c|c|c|c|c|c|}
\hline Kegiatan & $\begin{array}{c}\text { Activity } \\
\text { Time }\end{array}$ & $\begin{array}{c}\text { Early } \\
\text { Start }\end{array}$ & $\begin{array}{c}\text { Early } \\
\text { Finish }\end{array}$ & Late Start & $\begin{array}{c}\text { Late } \\
\text { Finish }\end{array}$ & Slack & $\begin{array}{c}\text { Standart } \\
\text { Deviation }\end{array}$ \\
\hline Project & 51 & & & & & & 33 \\
\hline Task 1 & 3 & 0 & 3 & 48 & 51 & 48 & 33 \\
\hline Task 2 & 1.17 & 0 & 1.17 & 49.83 & 51 & 49.83 & 17 \\
\hline Task 3 & 45 & 0 & 45 & 6 & 51 & 6 & 33 \\
\hline Task 4 & 2.17 & 0 & 2.17 & 48.83 & 51 & 48.83 & 17 \\
\hline Task 5 & 11 & 0 & 11 & 40 & 51 & 40 & 33 \\
\hline Task 6 & 8 & 0 & 8 & 43 & 51 & 43 & 33 \\
\hline Task 7 & 51 & 0 & 51 & 0 & 51 & 0 & 33 \\
\hline Task 8 & 10 & 0 & 10 & 41 & 51 & 41 & 33 \\
\hline Task 9 & 8 & 0 & 8 & 43 & 51 & 43 & 33 \\
\hline Task 10 & 20 & 0 & 20 & 31 & 51 & 31 & 33 \\
\hline Task 11 & 1.17 & 0 & 1.17 & 49.83 & 51 & 49.83 & 17 \\
\hline
\end{tabular}

Tabel 9. Hasil Perhitungan Varians dari Sofware POM QM

\begin{tabular}{|c|c|c|c|c|c|c|}
\hline Kegiatan & $\begin{array}{c}\text { Optimatic } \\
\text { Time }\end{array}$ & $\begin{array}{c}\text { Meat Likely } \\
\text { Time }\end{array}$ & $\begin{array}{c}\text { Pessimistic } \\
\text { time }\end{array}$ & $\begin{array}{c}\text { Activity } \\
\text { Time }\end{array}$ & $\begin{array}{c}\text { Standart } \\
\text { Deviation }\end{array}$ & Variance \\
\hline Task 1 & 2 & 3 & 4 & 3 & 33 & 11 \\
\hline Task 2 & 1 & 1 & 2 & 1.17 & 17 & 03 \\
\hline Task 3 & 44 & 45 & 46 & 45 & 33 & 11 \\
\hline Task 4 & 2 & 2 & 3 & 2.17 & 17 & 03 \\
\hline Task 5 & 10 & 11 & 12 & 11 & & 11 \\
\hline Task 6 & 7 & 8 & 9 & 8 & & 11 \\
\hline Task 7 & 50 & 51 & 52 & 51 & & 11 \\
\hline Task 8 & 9 & 10 & 11 & 10 & & 11 \\
\hline Task 9 & 7 & 8 & 9 & 8 & & 11 \\
\hline Task 10 & 19 & 20 & 21 & 20 & 33 & 11 \\
\hline Task 11 & 1 & 1 & 2 & 1.17 & 17 & 03 \\
\hline Project Results & & & & & & \\
\hline $\begin{array}{c}\text { Total of Critical } \\
\text { Activities }\end{array}$ & & & & & & 11 \\
\hline Square root of total & & & & & 33 & \\
\hline
\end{tabular}

Copyright (C) 2019, Kaizen : Management Systems \& Industrial Engineering Journal ISSN 15222-96806 (print), ISSN 155222-95973 (online) 


\section{Simpulan}

Berdasarkan hasil analisis dan pembahasan yang dilakukan maka dapat disimpulkan bahwa dari analisa produktivitas di PG Kremboong bagian pengolahan dengan menggunakan metode OMAX maka dapat diketahui indeks produktivitas terbaik tejadi pada bulan september 2018 yaitu sebesar 904. Sedangkan untuk produktivitas terburuk terjadi pada bulan Juni 2018 yaitu sebesar 164. Indeks perubahan terhadap produktivitas standar dapat diketahui bahwa produktivitas terbaik terjadi pada bulan September 2018 yaitu sebesar 201\%. Sedangkan untuk produktivitas terburuk terjadi pada bulan Juni 2018 yaitu sebesar $-45 \%$. Indeks perubahan terhadap produktivitas periode sebelumnya dapat diketahui bahwa produktivitas terbaik terjadi pada bulan Juli 2018 yaitu sebesar 375\%. Sedangkan untuk produktivitas yang terjadi pada bulan AgustusSeptember 2018 sama-sama memiliki nilai yaitu sebesar $8 \%$. Langkah perbaikan produktivitas guna perencanaan peningkatan produktivitas dimasa yang akan datang adalah dengan cara memprioritaskan kepada rasio yang memiliki nilai paling buruk untuk ditingkatkan melalui 3 tahapan peningkatan. Peningkatakan rasio 1, yaitu dengan efisiensi penggunaan jumlah tenaga kerja dan mengatur jadwal jam kerja dengan tepat sehingga memaksimalkan output gula yang dihasilkan. Peningkatan rasio 2, yaitu dengan memberikan pelatihan-pelatihan tentang penggunaan mesin sesuai dengan spesifikasi mesin dan waktu kerja mesin nya dan pemberian penghargaan kepada karyawan yang mencapai target. Peningkatan Rasio 3, yaitu dengan menggunakan energi yang seefisien mungkin sehingga dapat mengurangi energi yang dibutuhkan.

\section{Daftar Pustaka}

[1] W. I. Ervianto, Manajemen Proyek Kontruksi. Yogyakarta: Andi Offset, 2004.

[2] P. Mali, Improving Total Productivity. London: Jhon Wiley \& Sound, 1978.

[3] F. Agustina and N. A. Riana, "Analisis Produktivitas dengan Metode Objective Matrix (OMAX) di PT. X," J. Tek. dan Manaj. Ind., vol. 6, no. 2, pp. 150-158, 2011.

[4] R. J., Produktivitas dan Manajemen. Jakarta: Dewan produktivitas nasional dan The Asia Foundation, 1985.

[5] V. Gaspersz, Manajemen Produktivitas Total. Jakarta: Gramedia Pustaka Utama, 1998.

[6] D. Sumanth., Productivity Engineering and Mangement. New York: Mc Graw Hill Book Company, 1995.

[7] F. Tania and M. Ulkhaq, "Pengukuran dan Analisis Produktivitas di PT. Tiga Manunggal Synthetic Industries dengan Menggunakan Metode Objective Matrix ( OMAX )," Ind. Eng. Online J., vol. 5, no. 4, pp. $1-9,2016$. 